\title{
Influence of strain rate on deformation behaviour of an AX52 alloy processed by equal channel angular pressing (ECAP)
}

\author{
Z. Trojanová ${ }^{1, \dagger}$, K. Halmešová ${ }^{2}$, J. Džugan ${ }^{2}$, P. Palček ${ }^{3}$, P. Minárik ${ }^{1}$, P. Lukáć ${ }^{1}$ \\ †ztrojan@met.mff.cuni.cz

\begin{abstract}
${ }^{1}$ Charles University, Faculty of Mathematics and Physics, Ke Karlovu 5, 12116 Praha 2, Czech Republic
${ }^{2}$ Comtes FHT Průmyslová 995, 33441 Dobřany, Czech Republic

${ }^{3}$ University of Žilina, Faculty of Mechanical Engineering, Univerzitná 8215/1, 01026 Žilina, Slovakia
\end{abstract}

Cast AX52 magnesium alloy with $\mathrm{Al}$ and Ca was processed by equal channel angular pressing (ECAP) using A route and $1-8$ passes. The light and electron microscopy revealed a substantial microstructure refinement in the alloy. $\mathrm{Al}_{2} \mathrm{Ca}$ eutectics were found to be typical features of the microstructure. The ECAP procedure disintegrated eutectic particles. Miniaturized samples were cut from the ECAP-processed bulks. The samples with the tensile axis parallel to the extrusion direction were tested in tension at room temperature with initial strain rates of $0.001,1,10$ and $50 \mathrm{~s}^{-1}$. The offset yield stress increased with increasing number of passes. A rapid increase of deformation stresses was observed for the highest strain rate of $50 \mathrm{~s}^{-1}$. The activation volumes were estimated from the strain rate dependence of the offset yield stress. The strain rate sensitivity is influenced by the number of passes. A rapid increase of the activation volume at the highest strain rate indicates the change of the deformation mechanism. Limiting small values of the activation volume were found for the highest strain rates. Tensile tests at higher strain rates revealed unstable deformation behavior. This unstable deformation depends on the number of passes. Mechanisms operating at various strain rates are discussed in relation to the microstructure and number of ECAP passes.

Keywords: magnesium alloy, ECAP, strain rate dependence, texture, activation volume.

\section{Introduction}

It is well known that plastic deformation of polycrystalline materials is thermally activated. Parameters of the thermally activated process such as activation volume and strain-rate sensitivity parameter depend on the stress and temperature. The shear stress, $\sigma$, necessary for dislocation motion in the slip system is consider to have two components

$$
\sigma=\sigma_{i}+\sigma^{*}
$$

where $\sigma_{i}$ is the athermal component of the stress (internal stress) and, $\sigma^{*}$ is the temperature dependent component (effective stress). The internal stress acting on the dislocation is determined by the details of the internal structure at that moment. The changes of the applied stress are only due to changes of the effective stress. The effective shear stress $\sigma^{\star}$ acts on dislocations during their thermally activated motion when they overcome short range obstacles. For the rate of the plastic flow during straining, the Arrhenius equation can be written:

$$
\dot{\varepsilon}=\dot{\varepsilon}_{0} \exp \left[-\Delta G\left(\sigma^{\star}\right) / k T\right],
$$

where $\dot{\varepsilon}_{0}$ is a pre-exponential factor, $T$ is the absolute temperature and $k$ is the Boltzmann constant.

Magnesium and magnesium alloys have many potential applications because of their low density and good machinability. On the other hand, they generally exhibit only limited ductility at room temperature as a consequence of their hcp structure. $\mathrm{Mg}$-Al-Zn alloys, the most used $\mathrm{Mg}$ alloys, are applicable at temperatures up to $125^{\circ} \mathrm{C}$ [1]. Mg-Al-Ca (AX) alloys were developed for applications at temperatures up to $150{ }^{\circ} \mathrm{C}$ as a cheaper and lighter alternative to magnesium alloys containing rare elements. Most of die cast or squeeze cast magnesium alloys are $\mathrm{Mg}$ - $\mathrm{Al}$ alloys [2]. If the mass ratio of the $\mathrm{Ca} / \mathrm{Al}$ elements is lower than $0.8, \mathrm{Mg}_{17} \mathrm{Al}_{12}$ with the low eutectic temperature $\left(437^{\circ} \mathrm{C}\right)$ are not formed; improved creep properties are ascribed to the $(\mathrm{Mg}, \mathrm{Al})_{2} \mathrm{Ca}$ particles with an eutectic temperature of $517{ }^{\circ} \mathrm{C}$ and melting point of $710^{\circ} \mathrm{C}[3-7]$. Recently, Elamami and co-workers studied microstructure and phase selection in $\mathrm{Mg}$-Al-Ca-Mn cast alloys with $\mathrm{Ca} / \mathrm{Al}$ ratios from 0.58 to 0.91 [8]. The detailed analysis showed that $\mathrm{Mg}$-Al-Ca alloys contained various second phases of Laves type depending on $\mathrm{Ca} / \mathrm{Al}$ ratios and thermal treatment. Microstructure and mechanical properties of $\mathrm{Mg}$-Al based alloy with $\mathrm{Ca}$ addition has been reported by D. Wenwen et al. [9]. A strong relationship was observed between creep resistance and phase selection; a change from C15 + C36 Laves phases to C14 + C36 leads to a significant improvement of creep properties [8]. Commonly used alloys AX51 and AX52 exhibit good castability, better mechanical properties compared with AZ magnesium alloys and excellent creep resistance [2]. Further improvement of the mechanical properties is possible due to severe plastic deformation [10]. Equal channel angular pressing was found to be an effective method for preparation of materials with the microcrystalline grain structure and improved 
mechanical properties [11]. Disadvantages of this method are only small production volumes of severely deformed materials and strong texture that causes material anisotropy. Strain rate sensitivity (SRS) is an important material property that governs the rate dependent mechanical properties associated with deformation rate changes. The deformation mechanisms of magnesium alloys which are active during room temperature deformation are basal slip, prismatic slip, pyramidal slip and extension twinning [12]. Different SRSs were experimentally observed in $\mathrm{Mg}$ alloys for different deformation mechanisms [13]. If the main deformation mechanism is dislocation slip, the SRS is relatively high. On the other hand, mechanical twinning is nearly insensitive to the strain rate [13-15].

It is known that thermally activated processes, occurring during plastic deformation, are strongly strain rate sensitive. In the present study, cast $\mathrm{Mg}-\mathrm{Al}-\mathrm{Ca}$ alloy was processed by the ECAP and then deformed at various strain rates. The influence strain rate on the deformation stresses and thermally activated dislocation motion was studied.

\section{Experimental procedure}

AX52 alloy (nominal composition 5 wt. \% Al, 2 wt. \% Ca, balance $\mathrm{Mg}$ ) was manufactured by the squeeze cast technology. Billets with dimensions of $20 \times 10 \times 100 \mathrm{~mm}^{3}$ used for the ECAP processing were cut from the casting and then subjected to annealing at $390{ }^{\circ} \mathrm{C}$ for $22 \mathrm{~h}$. Equal channel angular pressing was performed in a rectangular channel $10 \times 10 \mathrm{~mm}^{2}$ (inner angle $\phi=90^{\circ}$ outer curvature $\left.\psi=0^{\circ}\right)$ at $250{ }^{\circ} \mathrm{C}$ and the machine speed of $10 \mathrm{~mm} / \mathrm{min}$. Material was underwent to 1, 2, 4 and 8 passes through the ECAP tool. According to literature data, the A route was chosen [16]. ECAPed samples will be hereafter depicted as $1 \mathrm{P}, 2 \mathrm{P}, 4 \mathrm{P}$ and $8 \mathrm{P}$ (after 1, 2, 4, and 8 passes in the ECAP tool). Samples for the tensile test were cut from the extruded prismatic bulk so that the tensile stress axis was parallel to the extrusion direction. Mechanical properties of samples were studied using a miniature testing technique. Due to small size of the testing specimens (tensile sample gauge section dimension of $0.5 \times 1.5 \times 4 \mathrm{~mm}^{3}$ ), relatively high strain rates can be attained using comparative slow loading speeds in comparison to standard dynamic tests [17]. The servo-hydraulic equipment MTS BIONIX (load capacity $25 \mathrm{kN}$, velocity of the actuator $1000 \mathrm{~mm} / \mathrm{s}$ and sampling rate $64 \mathrm{kHz}$ ) was employed. For optical strain measurement, a digital high-speed camera Phantom V711 with a maximum rate of $80 \mathrm{kFps}$ and resolution of $640 \times 480 \mathrm{px}$ was used. Tensile tests were performed at room temperature with initial strain rates of $0.001,1,10$ and $50 \mathrm{~s}^{-1}$. The true stresstrue strain curves were calculated from the force-elongation diagrams. The offset yield stress was determined as the stress at plastic strain of 0.002 . For each strain rate, three samples were tested; the mean value of the yield stress was used for further considerations.

The microstructure of samples was studied using a light microscope Olympus. Two sections of samples were observed: Longitudinal section (LS) parallel to the extrusion axis and the transversal section (TS) - perpendicular plane to the extrusion direction. The same sections were examined by scanning electron microscope (SEM) with the aim to reveal the microstructure details before and after ECA pressing. Quanta 200 FX scanning electron microscope equipped with EDAX EBSD camera; OIM software was utilized for EBSD observations and texture analysis.

\section{Experimental results}

\subsection{Microstructure characterization}

The microstructure of the as cast alloy, taken after annealing, is shown in Figs. 1 (light micrograph) and 2 (electron micrographs). Eutectic particles are the characteristic feature of this microstructure. They are situated mainly in the grain boundaries (Figs. 1, 2a and 2b), smaller eutectics were found inside of grains (Fig. 2b). Microstructure with the fine lamellar structure of particles decorating the grain boundaries is well visible in the scanning electron micrograph in Figure 2a. Such a microstructure is typical for AX alloys and it was observed by several authors [18-21]. Chemical analysis revealed that eutectics are $\mathrm{Al}_{2} \mathrm{Ca}$ particles.

Bigger particles in the grain boundaries fractured very probably during the squeeze casting process, as it is visible in Figs. $2 \mathrm{~b}$ and $2 \mathrm{c}$ taken on the transversal section.

Microstructure changes after the ECAP are shown in Figs. 3. Originally more or less uniaxial grains were after the first pass through the ECAP tool (and further passes) elongated in the extrusion direction. Bigger particles remained in the grain boundaries. Plenty of finer particles are visible within grains. New small grains were formed during the ECAP procedure inside of the old grains. These tiny grains are well visible in the right upper corner of Fig. $3 \mathrm{a}$. Number of new grains increased after the second pass as it is demonstrated in Fig. 3b. Many twins remained in the bigger old grains. The mean grain size decreased after the first pass down from 63 to $28 \mu \mathrm{m}$ (see Table 1). A rapid decrease of the grain size is observed after four passes (Table 1). The eutectics remained in the microstructure; belts of particles are oriented into the extrusion direction (Fig. 3c). The grain structure became more uniform.

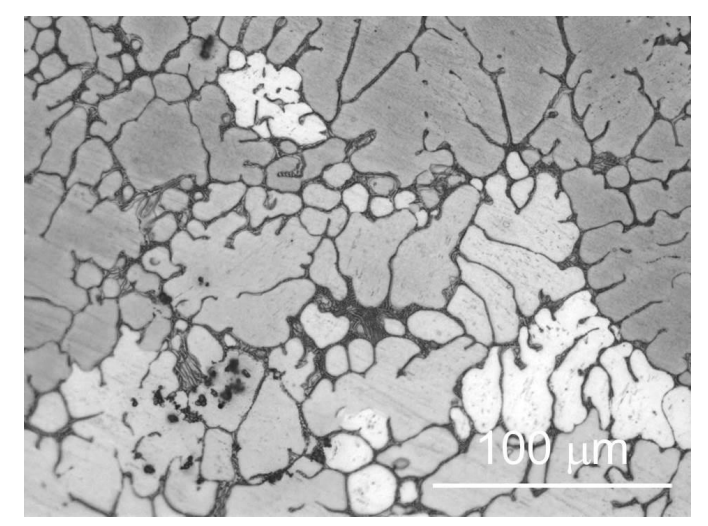

Fig. 1. Light micrograph of as cast alloy taken from the TS.

Table 1. The grain size of ECAPed samples estimated from the TS.

\begin{tabular}{|c|c|c|c|c|c|}
\hline Number of passes & 0 & 1 & \multicolumn{1}{c}{2} & \multicolumn{1}{c}{4} & 8 \\
\hline Grain size $(\mu \mathrm{m})$ & 63 & 28 & 21 & 4 & 3.4 \\
\hline
\end{tabular}


Further, slight grain refinement was observed after 8 passes as shown in Fig. 3d. Similar microstructure features were found in the transversal section. Small new grains after the first pass, roughly bimodal structure after the second pass and a significant grain refinement after 4 and 8 passes. Twins are visible in the coarser grains after 2 passes. The network of eutectics decorates the old grains (Fig. $3 e-3 g$ ). After 8 passes this network was breaded up as it is well visible in Fig. $3 \mathrm{~h}$.

The ECAP process disintegrated eutectic particles. It is obvious from electron micrographs (Figs. 4) taken after
8 passes. While in the squeeze cast alloy no pores were observed, new ones appeared in the microstructure after ECAP. It is well visible in Figs. 4 in both longitudinal (a) and transversal sections $(b, c)$. This is very probably a consequence of the debonding between the matrix alloy and hard particles. Figure $4 \mathrm{c}$ shows that the particles size is about $1 \mu \mathrm{m}$ or less after ECAP; the pore size is approximately the same.

The cast alloy with the more or less random orientation of grains exhibited no significant texture. The ECAP procedure caused an orientation of grains and formation

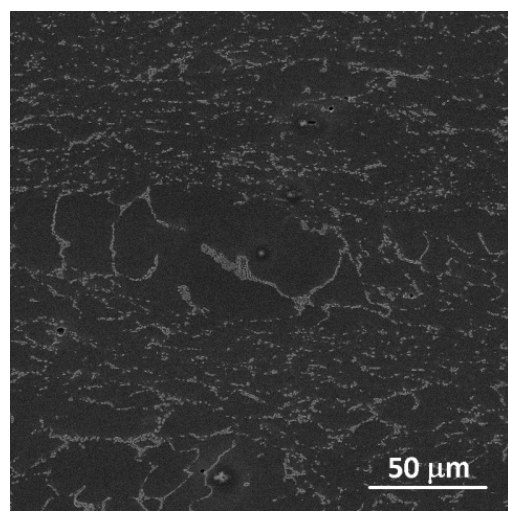

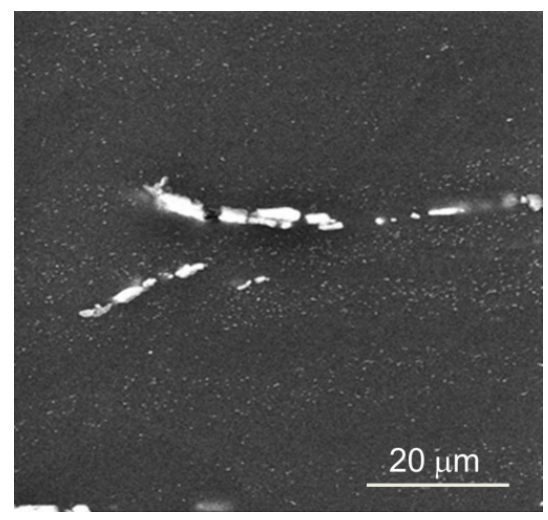

b

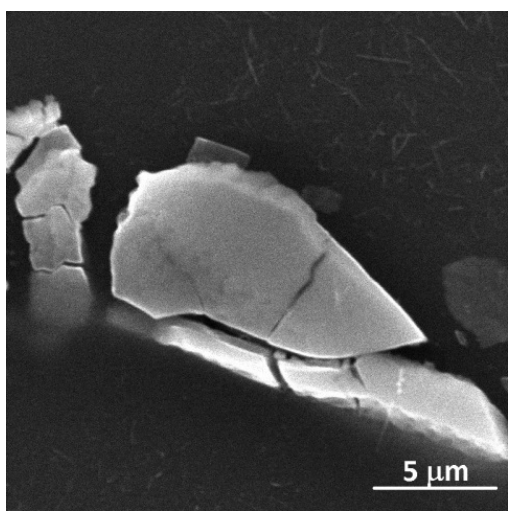

C

Fig. 2. Microstructure of the AX52 alloy after annealing: LS (a), TS (b, c).

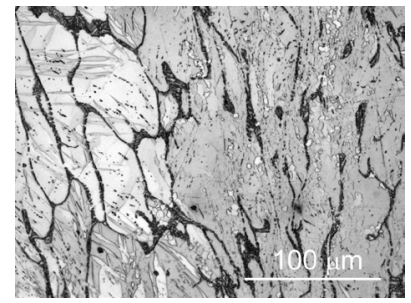

a

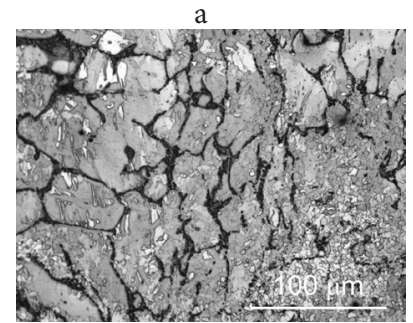

$\mathrm{e}$

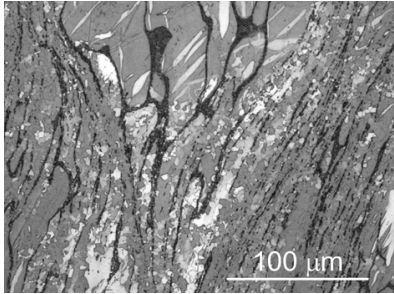

$\mathrm{b}$

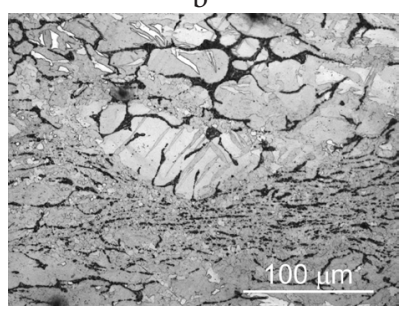

f

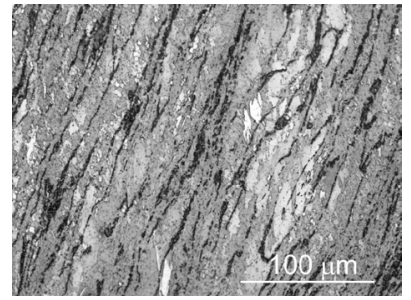

C

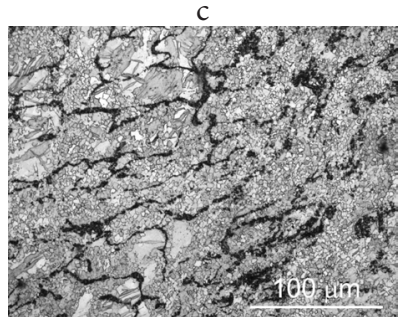

g

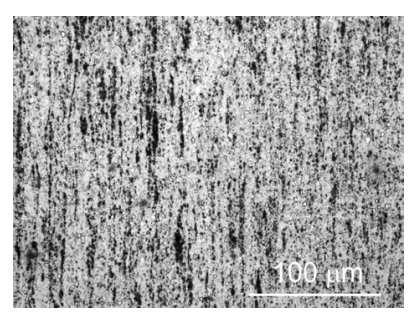

$\mathrm{d}$

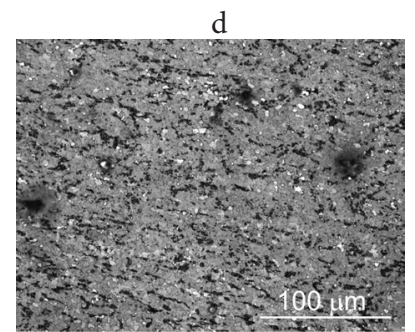

$\mathrm{h}$

Fig. 3. Alloy microstructure after ECAP observed on longitudinal section of $1 \mathrm{P}$ (a), 2P (b), 4P (c) and 8P samples (d) and on transversal section in $1 \mathrm{P}(\mathrm{e}), 2 \mathrm{P}(\mathrm{f}), 4 \mathrm{P}(\mathrm{g})$ and $8 \mathrm{P}(\mathrm{h})$ samples.

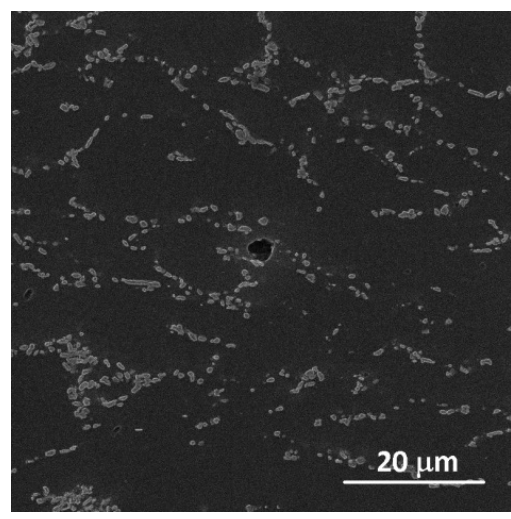

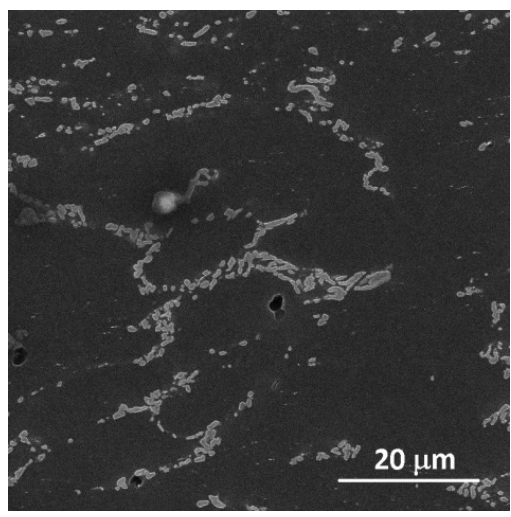

b

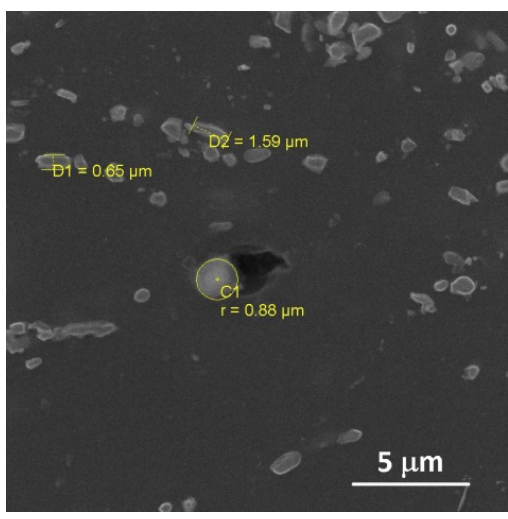

C

Fig. 4. Electron micrographs of the sample after $8 \mathrm{P}$ through the ECAP tool taken from the LS (a) and TS (b) and LS (c). 
relatively distinctive texture. Advanced texture taken from the transversal plane to the pressing direction is reported in Fig. 5. The texture development was mostly realised in the first pass, next passing changed the texture only slightly. Maxima positions remained stable after the following passes through the ECAP tool. From Figs. 5, it is clear that texture developed during ECAP differs from the texture usually observed after normal extrusion. The (0002) pole figures show a maximum located at $90^{\circ}$ from the extrusion direction indicating that the basal planes rotated into position parallel to the extrusion direction and the channel wall with the random rotation of the prismatic planes along the $c$-axis of the hexagonal cell. Some side maximum observed after the first pass in the bottom part of Fig. 5a indicates that a part of basal planes is lying nearly parallel to the theoretical maximum shear stress plane. This side maximum vanished after 4 and 8 passes.

\subsection{Tensile tests}

The true stress-true strain curves obtained for as cast alloy were nearly smooth and the strain rate sensitivity of the yield stress was small. Analogous curves measured for ECAPed samples were smooth only for the lowest strain rate of $0.001 \mathrm{~s}^{-1}$. The curves obtained at higher strain rates exhibited wave like character as it is visible in Fig. 6, where the curves obtained for $8 \mathrm{P}$ sample at various strain rates are reported.

The yield stress of tested samples increases with increasing number of passes as shown in Fig. 7. The yield stress increase is significant after 1, 2 and 4 passes. The difference between the yield stresses found after the $4^{\text {th }}$ and $8^{\text {th }}$ passes is only marginal. The yield stress dependence on the number of passes is shown in Fig. 7 for the lowest and highest strain rates. A great difference between both curves indicates the high SRS of the material. It is better to see in Fig. 8 where the yield stresses of ECAPed samples obtained for all strain rates are shown. The SRS is moderate at the strain rates from 0.001 to $10 \mathrm{~s}^{-1}$; while a rapid SRS increase was observed between the strain rates 10 and $50 \mathrm{~s}^{-1}$ (see Fig. 8). This increase was observed for all ECAPed samples. The SRS estimated for the as cast alloy was only weak without rapid increase at the highest strain rate.
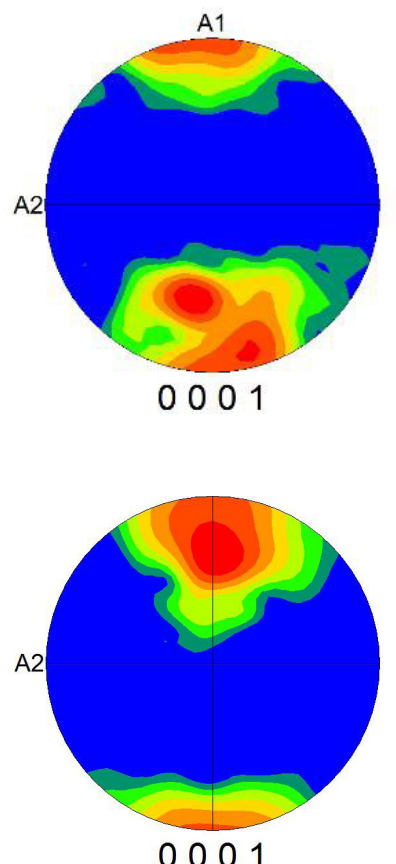

0001

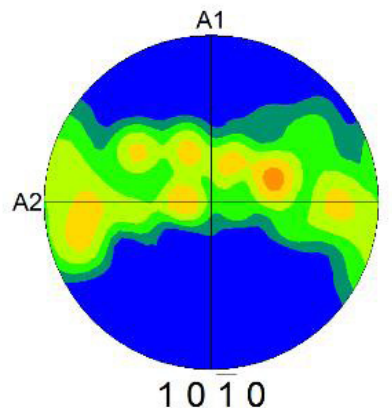

a

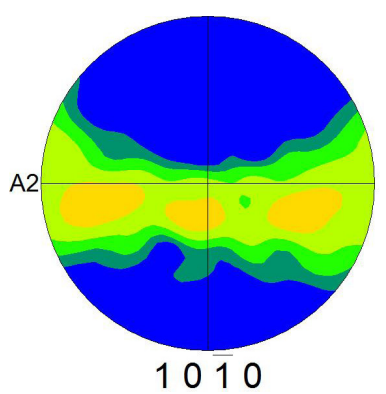

c
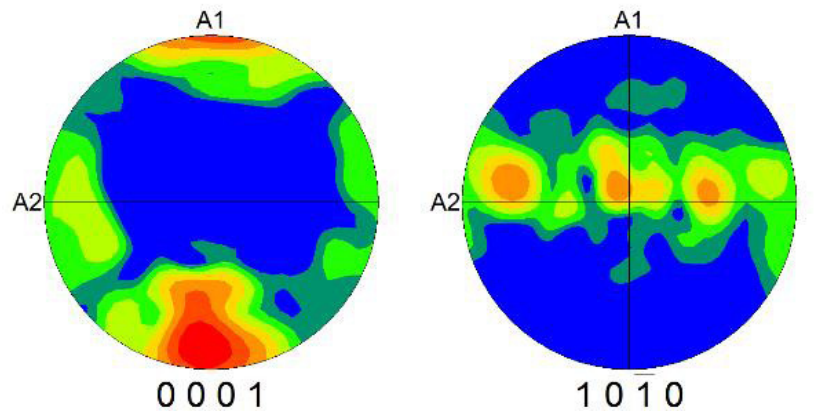

b
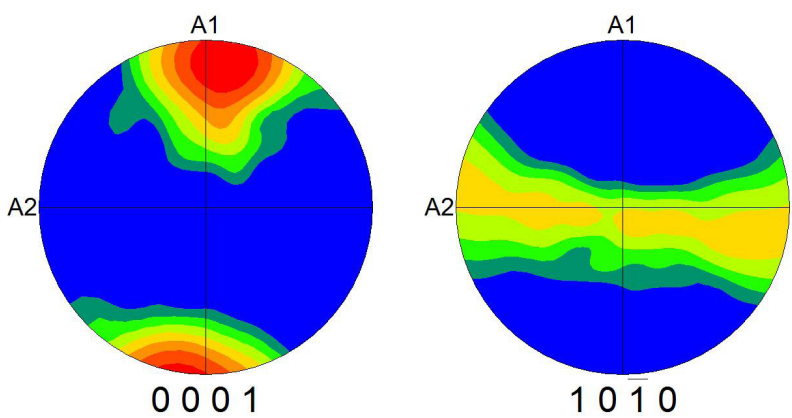

$\mathrm{d}$

Fig. 5. Texture developed in the alloy after the first (a), $2^{\text {nd }}(\mathrm{b}), 4^{\text {th }}(\mathrm{c})$ and $8^{\text {th }}(\mathrm{d})$ pass in the ECAP tool.

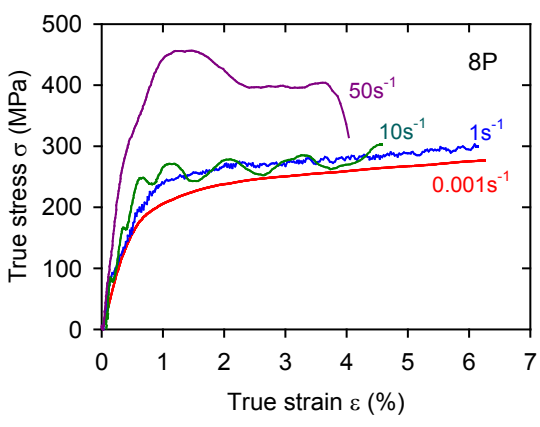

Fig 6. True stress-true strain curves obtained for $8 \mathrm{P}$ sample and four strain rates.

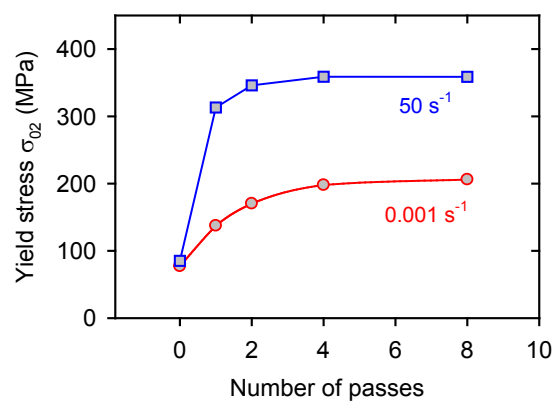

Fig 7. The yield stress depending on the number of passes estimated for the strain rates of 0.001 and $50 \mathrm{~s}^{-1}$.

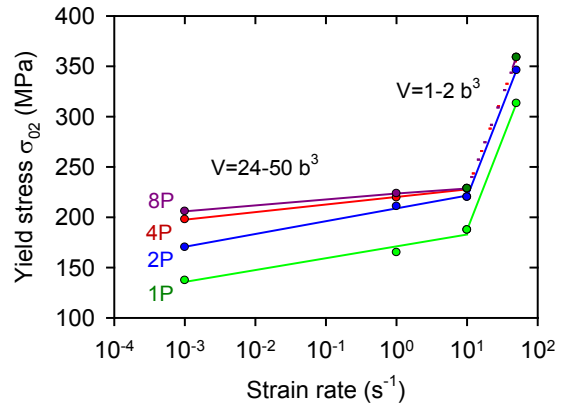

Fig 8. The yield stress depending on the strain rate obtained for ECAPed samples. 


\subsection{Activation volume}

The slope of the strain rate dependence $\partial \sigma / \partial \ln \dot{\varepsilon}$ shown in Fig. 8 may be used for calculation of the apparent activation volume according to:

$$
V_{a}=k T\left(\frac{\partial \ln \dot{\varepsilon}}{\partial \sigma}\right)_{\varepsilon} .
$$

The differential quotient $\partial \ln / \partial \mathrm{s}$ can be rewritten as:

$$
\frac{\partial \ln \dot{\varepsilon}}{\partial \sigma^{*}}=\left(\frac{\partial \ln \dot{\varepsilon}}{\partial \sigma}\right)\left(\frac{\partial\left(\sigma_{i}+\sigma^{*}\right)}{\partial \sigma^{*}}\right)
$$

and considering that the internal stress $\sigma_{i}$ is constant, it may be used for calculation of the activation volume. Values of the activation volume calculated for ECAPed samples were, as usual, expressed in dimensionless units of $V / b^{3}$. The activation volume estimated in the strain rate range of $0.001-10 \mathrm{~s}^{-1}$ increases with the number of ECAP passes from $V=24 b^{3}$ (1P) up to $50 b^{3}$ (8P). Such values of the activation volume tens of $b^{3}$ are typical for metallic polycrystals. Similar results were found also for many magnesium alloys [22]. The activation volumes found at the highest strain rates are approximately the same for all ECAPed samples, independent of number of passes, achieving low values of $V=1-2 b^{3}$.

\section{Discussion}

From Figs. 7 and 8, it follows that the yield stress increases with increasing number of passes. This increase may be caused by an increase in the dislocation density and simultaneously grain size refinement. The evolution of dislocation density after ECAP processing was found to be similar in various magnesium alloys. After a substantial increase after the first pass the dislocation density continuously decreases with increasing ECAP deformation [16,23-25]. Simultaneously, the grain size of samples decreases with increasing number of passes. The dependence of the flow stress on the grain size may be expressed by the Hall-Petch relationship:

$$
\sigma_{y}=\sigma_{0}+m_{T} K_{y} d^{-1 / 2},
$$

where $\sigma_{y}$ is the yield stress, $\sigma_{0}$ is friction stress, $m_{T}$ the Taylor factor, $K_{y}$ is the microstructural stress intensity, and $d$ is average grain size. Prasad and Armstrong showed that $K_{y}$ relates to the thermally activated stress for the most difficult slip systems in a polycrystal [26]. Such difficult slip systems in Mg alloys, are non-basal slip systems while the basal slip is the easiest. If $\tau_{C}$ is the critical resolved shear stress for the non-basal slip system, $K_{y}$ is the stress intensity factor on the tip of the pile-up, needed to the activation of a non-basal slip system [27].

$$
K_{y}=C_{1}\left(\frac{m_{S} G b \tau_{C}}{1-v}\right)^{1 / 2},
$$

where $m_{S}$ is the Sachs orientation factor for accommodating system, $G$ shear modulus, $v$ Poisson constant and $C_{1}$ a numeric constant. Relatively strong sensitivity of the cast $\mathrm{Mg}$ to the grain size strengthening, $K_{y} \sim 10 \mathrm{MPa} \cdot \mathrm{mm}^{1 / 2}$, was estimated by several authors e.g. $[28,29]$. This indicates the fact that the pile-ups formation mechanism plays an important role in the deformation process of magnesium materials. For extruded $\mathrm{Mg}$, tested in tension, values of $K_{y}$ were found lower 2-6 MPa $\cdot \mathrm{mm}^{1 / 2}$ depending on the grain size range in which the Hall/Petch relation was analysed [30]. $K_{y}$ for rolled $\mathrm{Mg}$ with the grain size from 10 to $250 \mu \mathrm{m}$ exhibited a higher value of $9.2 \mathrm{MPa} \cdot \mathrm{mm}^{1 / 2}$ [31]. The calculation of the Taylor and Sachs factors, $m_{T}, m_{S}$, for textured hexagonal metals is a complex problem; as to authors knowledge, was not satisfactorily solved [32]. If the main deformation mechanism is twinning the sensitivity to the grain size is more significant because the stress necessary for the twinning activation is higher in smaller grains than the stress required activating slip. Then the $K_{y}$ parameter is higher in materials where the flow is controlled by twinning than that for the slip deformation. The slope of the Hall-Petch plot estimated from $1 \mathrm{P}-8 \mathrm{P}$ samples was found to be $4.9 \mathrm{MPa} \cdot \mathrm{mm}^{1 / 2}$. This value corresponds very well with the value of $4.4 \mathrm{MPa} \cdot \mathrm{mm}^{1 / 2}$, estimated for the ECAPed AZ91 magnesium alloy with the grain size between 1 and $100 \mu \mathrm{m}$ [33].

The SRS $m=\partial \ln \sigma / \partial \ln \dot{\varepsilon}$ was calculated from the strain rate dependences of $\sigma$ reported in Fig. 8. In the strain rate range from 0.001 to $10 \mathrm{~s}^{-1}, m$ decreases with increasing number of passes. In the strain rate range between 10 and $50 \mathrm{~s}^{-1}$, the SRS was approximately the same $m=0.28$ for all ECAPed samples. This value is much higher than that estimated in the range of low and moderate strain rates. Theory of the thermally activated processes occurring during plastic deformation predicts that the activation volume is inversely proportional to the effective stress component $\sigma^{\star}$. (This component may be estimated for example in the stress relaxation experiments [34]). Kocks et al. formulated an empirical relation for the dependence of the Gibbs enthalpy $\Delta G$ on the effective stress $\sigma^{\star}$ in the following form [35]:

$$
\Delta G=\Delta G_{0}\left[1-\left(\frac{\sigma^{*}}{\sigma_{0}^{*}}\right)^{p}\right]^{q},
$$

where $\Delta G_{0}$ and $\sigma_{0}^{*}$ are Gibbs enthalpy and the effective stress at $0 \mathrm{~K}$, respectively. $p$ and $q$ are phenomenological parameters reflecting the shape of a local obstacle for the dislocation motion. The activation volume is done in the general thermodynamic as $V=\left(\partial \Delta G / \partial \sigma^{*}\right)_{T}$. Then the stress dependence of the activation volume may be expressed as

$$
V=k T \frac{\partial \ln \frac{\dot{\varepsilon}}{\dot{\varepsilon}_{0}}}{\partial \sigma_{0}^{*}}=\frac{\Delta G_{0} p q}{\sigma_{0}^{*}}\left[1-\left(\frac{\sigma^{*}}{\sigma_{0}^{*}}\right)^{p}\right]^{q-1}\left(\frac{\sigma^{*}}{\sigma_{0}^{*}}\right)^{p-1} .
$$

Trojanová and Lukáč analysed thermally activated processes in several $\mathrm{Mg}$ alloys and showed that equation (8) is a "master curve" for the stress dependence of the activation volume common for Mg alloys [22]. They have reported that the main thermally activated process occurring in magnesium alloys at room and higher temperatures is the glide of dislocations on non-basal planes. Similar conclusions were given in [36] where authors studied the nature of the thermally activated processes in microcrystalline magnesium. The grain size in our $4 \mathrm{P}$ and $8 \mathrm{P}$ samples is small enough for the grain boundary sliding [37]. Koike et al. [38] estimated the contribution of grain boundary sliding in an AZ31 alloy with the grain size of $8 \mu \mathrm{m}$ deformed at room temperature (strain rate $10^{-3} \mathrm{~s}^{-1}$ ) to be about $8 \%$. This mechanism is very probably 
the reason for the observed increase of the activation volume in the $8 \mathrm{P}$ sample compared with the $1 \mathrm{P}$ sample.

The observed wavy shape of the stress-strain curves (see Fig. 7) indicates that the deformation process is not stable. Non-monotonous plastic deformation of metallic materials may be observed at various temperatures including very low temperatures. Unstable deformation observed at elevated temperatures during plastic deformation of alloys is known as the Portevin-LeChâtelier effect. Unstable deformation can be influenced by the sample geometry, microstructure, substructure, surface state, sample thermal properties and deformation conditions as strain rate, temperature and deformation apparatus stiffness. The observed texture of samples having basal planes parallel to the tensile axis indicates very low Schmid factor for deformation in the basal plane and therefore a difficult activation of basal slip. Krajňák et al. performed analysis of distribution dislocations in the particular slip systems in an AX41 alloy subjected to ECAP procedure [16]. They estimated that most dislocations (80-95\%) in all ECAP samples have <a>-type Burgers vector. Because of low Schmid factor for basal slip system, prismatic and pyramidal slips are likely activated. $<$ a $>$ dislocations lying in basal planes are forest dislocations for both prismatic and pyramidal slip, respectively. A role of the dislocation forest in hcp structures with the main basal slip was studied by Lavrentev [39]. He showed that an increased forest dislocation density by the prestraining in prismatic slip system led to an unstable plastic deformation in the basal plane. Similar experiments were conducted by Dosoudil et al. [40]. The authors observed unstable plastic deformation in basal slip of Zn single crystals with increased density of forest dislocations. Simultaneously, acoustic emission measurements detected large bursts signal against the background observed during smooth deformation. These results showed that large dislocation ensembles are moving after sudden release of the stress. Forest dislocations are local obstacles for dislocation motion, which may be overcome at low and medium strain rates by the thermal activation. Limiting low value of the activation volume, observed at highest strain rates, indicates that the dislocation motion is not thermally activated; it is very probably viscous. Lower or none assistance of thermal activation to dislocation motion and formation of pile ups is the reason for significant increase of the deformation stress. If the activation of a Frank-Read source or grain boundary source occur under conditions of stable planar glide, dislocations can form a dynamic pile-up able to move at increasing speed and decreasing levels of the applied stress because of the development of stress concentration ahead of the moving dislocations. This may spontaneously lead to an avalanche of dislocations that meets the general requirement for unstable tensile flow, a drop in the load as observed at higher strain rates.

An alternative phenomenological explanation of unstable plastic deformation was published by Eremin and Natsik [41]. They searched for criterion of instability of thin samples deformed in tension. They estimated that in the case when inequality $\ell>\sqrt{ } A$ ( $\ell$ is the sample length and $A$ the sample crosssection) takes place, the evolution of the geometrical instability should start when constrictions of the characteristic dimension along the sample achieve some critical value of $\sqrt{ } A$.
The deformation process acquires the wave-character at the moment when following inequality takes place

$$
\sigma>\theta+2 K / \pi^{2} \ell
$$

where $\theta$ is the work hardening coefficient and $K$ machine stiffness. From equation (9), it can be seen that the sample stability in tension depends on various factors: kinetic behavior of the material characterized by the work hardening coefficient, sample geometry and the machine stiffness.

\section{Conclusions}

- ECAP process substantially refined the microstructure of the cast AX52 alloy.

- The tensile yield strength increases with increasing number of passes up to 4 passes, then a saturation effect was observed.

- Strain rate sensitivity rapidly increased in the strain rate range of $10-50 \mathrm{~s}^{-1}$.

- The activation volume estimated for strain rate between 0.001 and $10 \mathrm{~s}^{-1}$ achieves values of tens $b^{3}$.

- Limiting low value of the activation volume and wavy character of the stress strain curves obtained at the highest strain rates indicate that the dislocation motion is very probably viscous with sudden release of dislocation pile ups.

Acknowledgements. Authors are grateful to the Grant Agency of the Czech Republic for the financial support (Project Nr. 15/11879S). This paper is dedicated to the memory of Oscar Akramovich Kaibyshev, founder and former director of Institute for Metals Superplasticity Problems of the Russian Academy of Sciences, well known researcher in superplasticity.

\section{References}

1. R. Nimomiya, T. Ojiro, K. Kubota. Acta Metall. Mater. 43, 669 (1995). DOI: 10.1016/0956-7151(94)00269-N

2. M. Pekguleryuz. In: Magnesium Alloys and Their Appications (Ed.K. U. Kainer). DGM, WILEY-VCH, Weinheim (2003) p. 65.

3. A. A. Luo. Inter. Mater. Reviews. 49, 2004, 13.

4. M. O. Pekguleryuz, A. A. Kaya. Adv.Eng. Mater. 5, 866 (2004). DOI: 10.1002/adem.200300403

5. A. A. Luo, B. R. Powell, A. K. Sachdev. Intermetallics. 24, 22 (2012). DOI: 10.1016/j.intermet.2012.01.001

6. H. Gjestland, G. Nussbaum, G. Regazzoni, O. Lohne, O. Bauger. Mater. Sci.Eng. A. 134, 1197 (1991). DOI: 10.1016/0921 - 5093 (91) 90954-L

7. Y. Terada, N. Ishimatsu, R. Sota, T. Sato, K. Ohori. In: Magnesium Alloys. Trans Tech Publications (2003) p. 459.

8. H. A. Elamami, A. Incesu, K. Korgiopulos, M Pekguleryuz, A. Gungor. J. Alloys Compd. 764, 216 (2018). DOI: 10.1016/j.jallcom.2018.05.309

9. D. Wenwen, S. Yangshan, M. Xuegang, X. Feng, Z. Min, W. Dengyun. Mater. Sci.Eng. A. 356, 1 (2003). DOI: 10.1016/S0921-5093(02)00551-8

10. Y. Estrin, A. Vinogradov. Acta Mater. 61, 782 (2013). DOI: $10.1016 /$ j.actamat.2012.10.038

11. H. K. Lin, J. C. Huang, T. G. Langdon. Mater. Sci. Eng. A. 
250, 402 (2005). DOI: 10.1016/j.msea.2005.04.018

12. S. R. Agnew, O. Duygulu. Int. J. Plast. 21, 1161 (2004). DOI: $10.1016 /$ j.ijplas.2004.05.018

13. A.S. Khan, A. Pandey, T. Gnäupel-Herold, R.K. Mishra. Int. J. Plast. 27, 688 (2011). DOI: 10.1016/j.ijplas.2010.08.009

14. L. Li, O. Muránsky, E. A. Flores-Johnson, S. Kabra, L. Shen, G. Proust. Mater. Sci. Eng. A. 684, 37 (2017). DOI: 10.1016/j.msea.2016.12.015

15. H. Wang, P. Wu, S. Kurukuri, M. J. Worswick, Y. Penga, D. Tanga, D. Li. Int. J. Plasticity. 107, 207 (2018). DOI: $10.1016 /$ j.ijplas.2018.04.005

16. T. Krajňák, P. Minárik, J. Gubicza, K. Máthis, R. Kužel, M. Janeček. Mater. Charact. 123, 282 (2017). DOI: 10.1016/j.matchar.2016.11.044

17. M. Rund, R. Procházka, P. Konopik, J. Džugan, H. Folgar. In: ICSI 20151ST Int. Conf. Struct. Integr. FUNCHAL (Eds. P. M.G.P. Moreira, P.J. Tavares). ELSEVIER SCIENCE, Amsterdam, Netherlands (2015) p. 410.

18. S.W. Xu, N. Matsumoto, K. Yamamoto, S. Kamado, T. Honma, Y. Kojima. Mater. Sci. Eng. A. 509, 105 (2009). DOI: 10.1016/j.msea.2009.02.024

19. S. M. Liang, R.S. Chen, J. J. Blandin, M. Suery, E.H. Han. Mater. Sci.Eng. A. 480, 365 (2008). DOI: 10.1016/j.msea.2007.07.025

20. Z.T. Li, X. D. Zhang, M.Y. Zheng, X.G. Qiao, K. Wu, C. Xu, S. Kamado. Mater. Sci. Eng. A. 682, 423 (2017). DOI: $10.1016 /$ j.msea.2016.11.026

21. D. Xiao, Z. Chen, X. Wang, M. Zhang, D. Chen, Mater. Sci.Eng. A. 660, 166 (2016). DOI: 10.1016/j.msea.2016.03.001

22. Z. Trojanová, P. Lukáč. Int. J. Mater. Res. 100, 270 (2009). DOI: $10.3139 / 146.110054$

23. P. Minárik, R. Král, J. Čížek, F. Chmelík. Acta Mater. 107, 83 (2016). DOI: 10.1016/j.actamat.2015.12.050

24. L. Balogh, R.B. Figueiredo, T. Ungár, T.G. Langdon. Mater. Sci.Eng. A. 528, 533 (2010). DOI: $10.1016 /$ j.msea.2010.09.048
25. J. Vrátná, M. Janeček, J. Čížek, D. J. Lee, E. Y. Yoon, H.S. Kim, J. Mater. Sci. 48, 4705 (2013). DOI: $10.1007 / \mathrm{s} 10853-013-7151-\mathrm{x}$

26. Y.V. R. K. Prasad, R.W. Armstrong. J. Sci. Ind. Res. 32, 314 (1972).

27. R. W. Armstrong, S. M. Walley. Int. Mater. Rev. 53, 105 (2008). DOI: 10.1179/174328008X277795

28. R.Armstrong,R. M.Douthwaite,I.Codd,N. J.Petch.Philos. Mag. 7, 45 (1962). DOI: 10.1080/14786436208201857

29. C.H. Cáceres, G.E. Mann, J.R. Griffiths, Metall. Mater. Trans. A. 42A, 1950 (2011). DOI: $10.1007 /$ s11661-010-0599-2

30. D. V Wilson, J. A. CHapman. Philos. Mag. 8, 1543 (1963). DOI: $10.1080 / 14786436308207317$

31. N. Ono, K. Nakamura, S. Miura. Mater. Sci. Forum, 419-422, $195 \quad$ (2003). DOI: 10.4028/www.scientific.net/MSF.419-422.195

32. C.H. Cáceres, P. Lukáč. Philos. Mag. 88, 977 (2008). DOI: 10.1080/14786430801968611

33. M. Mabuchi, Y. Chino, H. Iwasaki, T. Aizawa, K. Higashi. Mater. Trans. 42, 1182 (2001).

34. Z. Trojanová, P. Lukáč, K. U. Kainer. Adv.Eng. Mater. 9, 370 (2007). DOI: 10.1002/adem.200700018

35. U. F. Kocks, A. S. Argon, M. F. Ashby. Prog. Mater. Sci. 19, 1 (1975). DOI: 10.1016/0079-6425(75)90007-9

36. Z. Trojanová, Z. Drozd, P. Lukáč, K. Máthis, H. Ferkel, W. Riehemann. Scr. Mater. 42, 1095 (2000). DOI: 10.1016/S1359-6462(00)00342-0

37. R.S. Kottada, A.H. Chokshi. Metall. Mater. Trans. A. 38A, 1743 (2007). DOI: 10.1007/s11661-007-9190-x

38. J. Koike, R. Ohyama, T. Kobayashi, M. Suzuki, K. Maruyama. Mater. Trans. A. 44, 445 (2003).

39. F. F. Lavrentev. Mater. Sci. Eng. 46, 191 (1980). DOI: 10.1016/0025-5416(80)90175-5

40. J. Dosoudil, Z. Trojanová, P. Lukáč, F. Chmelík, F. F. Lavrentev. Kovove Mater. 33, 181 (1995).

41. V.I. Eremin, V.D. Natsik. Scr. Metall. Mater. 26, 47 (1992). DOI: 10.1016/0956-716X(92)90366-M 